\title{
Experimental study of wind loads on unique buildings and structures in Russia
}

\author{
Olga Poddaeva ${ }^{1}$, Pavel Churin ${ }^{1, *}$ and Ilya Dunichkin ${ }^{1}$ \\ ${ }^{1}$ Moscow State University of Civil Engineering, Yaroslavskoe sh. 26, 129337 Moscow, Russia
}

\begin{abstract}
Design and construction of unique buildings and structures (sports arenas, airport complexes, business centres, etc.) from an engineering point of view is a very difficult task as in most cases these facilities have an original architectural form. Therefore, consideration of wind loads is an important part of the design. The paper presents the definition of wind load for two complex of airport. Researches was applied the combined calculation an experimental method. During the experimental study a wind tunnel architectural and construction type NRU MSUCE was used. Numerical simulations were performed using the software package ANSYS. The result of research on each object are integral aerodynamic loads on the object (coefficients $\mathrm{Cx}, \mathrm{Cy}, \mathrm{Cmz}$ ) and picture of the distribution of aerodynamic pressure coefficient $\mathrm{Cp}$ obtained in the numerical simulation. In conclusion, we discuss the possible formation of deposits of snow and recommendations to eliminate them from the roof of researched objects.
\end{abstract}

\section{Introduction}

Modern Russian policy is aimed at promoting the different types of sports. Since 2014 our country carried out many international sporting events, including the Olympic Games in Sochi. At present, we are actively preparing for the FIFA World Cup 2018. In this regard is actively built a unique building objects - sports arenas, football stadiums, airport complexes, and others.

The Russian and foreign documents, regulating the accounting of various loadings and impacts on constructions, for unique buildings and constructions recommend carrying out researches of wind loading in specialized wind tunnels [1,2,3]. In 2013, on the basis of the Moscow State University of Civil Engineering was put into operation the first Russian wind tunnel for buildings and constructions corresponding to modern requirements.

\section{Research method}

For the purpose of minimization of labor costs and time of carrying out researches was applied the combined calculation an experimental method. Calculation and experimental approach combines the advantages of physical and numerical modeling, and is the most optimal and efficient in solving problems of building aerodynamics.

\footnotetext{
* Corresponding author: pashok@,inbox.ru
} 
This method involves experimental simulation in the wind tunnel and numerical modeling in a specialized software package (in this case, was used ANSYS) $[5,8]$. In the process of experimental simulation are defined integral aerodynamic forces, moments, and aerodynamic pressure coefficients at the control points on the surface of the models. In the process of numerical simulation was defined the complete picture of the distribution of the aerodynamic pressure coefficients on the surfaces of the models. This approach allows for the verification of the numerical model with the results of more reliable experimental studies, and at the same time to obtain the most complete information about the wind loads.

\section{Objects of study}

As objects of research are chosen the projected airport complexes in the large regional centers - Rostov-on-Don and Perm.

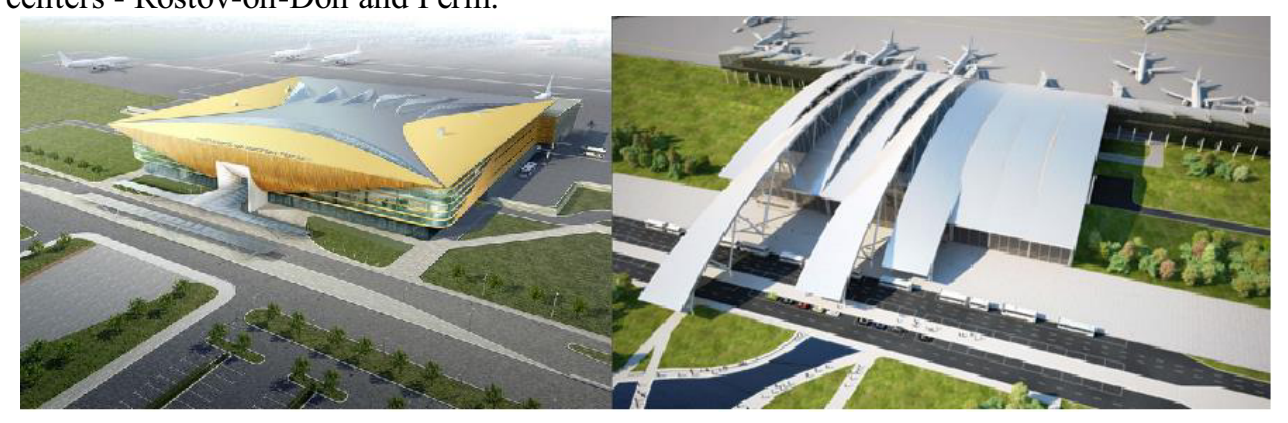

Fig. 1. Air terminal complex in Perm and in Rostov-on-Don.

\section{Prototyping}

One of the most difficult stages of carrying out such researches is prototyping. This is related to the necessity of accurately reproduce complex spatial geometric shape of the roof of the investigated object. Currently, this problem is solved by creating a 3D model of the object under study and subsequent printing on a $3 \mathrm{D}$ printer.

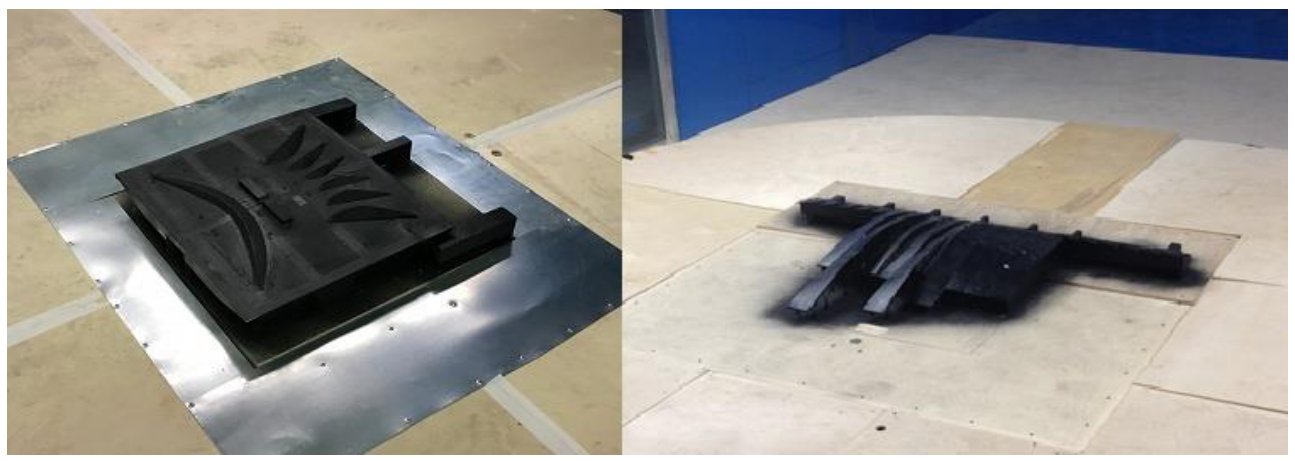

Fig. 2. Models of air terminal complex The process of research.

\section{The process and results of research}

In the process of research, a scale model airport in the wind tunnel to match full-scale Reynolds number $\left(\operatorname{Re}_{\mathrm{nat}} \approx 2 * 10^{7}\right)$ is unattainable. However, for this class of bodies (bluff) is 
characterized by the existence of "self-similarity on Reynolds's number" range when with increasing $\mathrm{Re}$ dimensionless characteristics of a flow around a body practically cease to depend on this parameter $[4,6]$.

To determine the self-similarity range for the investigated object model were performed auxiliary weight test by gradually increasing the flow velocity in the tunnel from $\mathrm{V} \infty=5$ to $30 \mathrm{~m} / \mathrm{s}$. The dependences obtained allows us to conclude that for such models at $\mathrm{V} \infty \geq 20$ $\mathrm{m} / \mathrm{s}(\operatorname{Re} \geq 0.29 * 106)$ we have the self-similarity of the Reynolds number.

Measured using tensor-pressure sensors on the surface of airports models in drainage points gives an indication of the distribution of the facades and roof of aerodynamic pressure of the object at an air flow attack angles from 0 to 360 degrees with a pitch of 15 degrees.

Spectral analysis of pressure fluctuations in the drainage points allowed verifying the numerical simulation. These data are reusable. In addition to the definition of pressure on the building envelope airports is possible to perform an assessment of bioclimatic comfort of the adjacent space, which is important for the comfort and safety of the occupants of the buildings near airports $[6,8]$.

Using six-component force-torque sensors and ATI DAQ F/T software defined Fx, Fy, $\mathrm{Fz}, \mathrm{Mx}, \mathrm{My}$ and $\mathrm{Mz}$ - the total force and torques along the axes $\mathrm{X}, \mathrm{Y}$ and the $\mathrm{Z}$, respectively, and calculated the $\mathrm{Cx}, \mathrm{Cy}, \mathrm{Cz}, \mathrm{CMx}, \mathrm{CMy}$ and $\mathrm{CMz}$ - total aerodynamic coefficients [9].

The result of research on each object are integral aerodynamic loads on the object (coefficients $\mathrm{Cx}, \mathrm{Cy}, \mathrm{Cmz}$ ), and picture of the distribution of aerodynamic pressure coefficient $\mathrm{Cp}$ obtained in the numerical simulation.

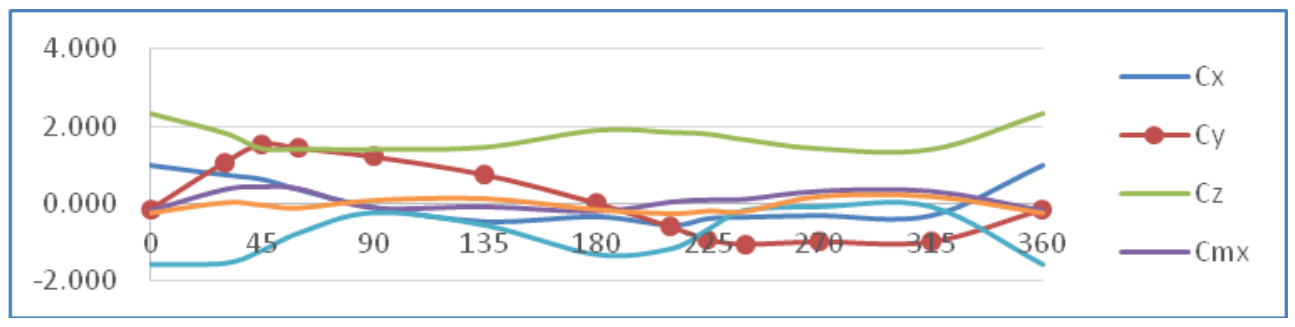

Fig. 3. The schedule of aerodynamic coefficients dependence $\mathrm{Cx}, \mathrm{Cy}, \mathrm{Cz}, \mathrm{Cmx}, \mathrm{Cmy}, \mathrm{Cmz}$ at change of attack angle from $0^{\circ}$ to $360^{\circ}$ (Rostov-on-Don). 


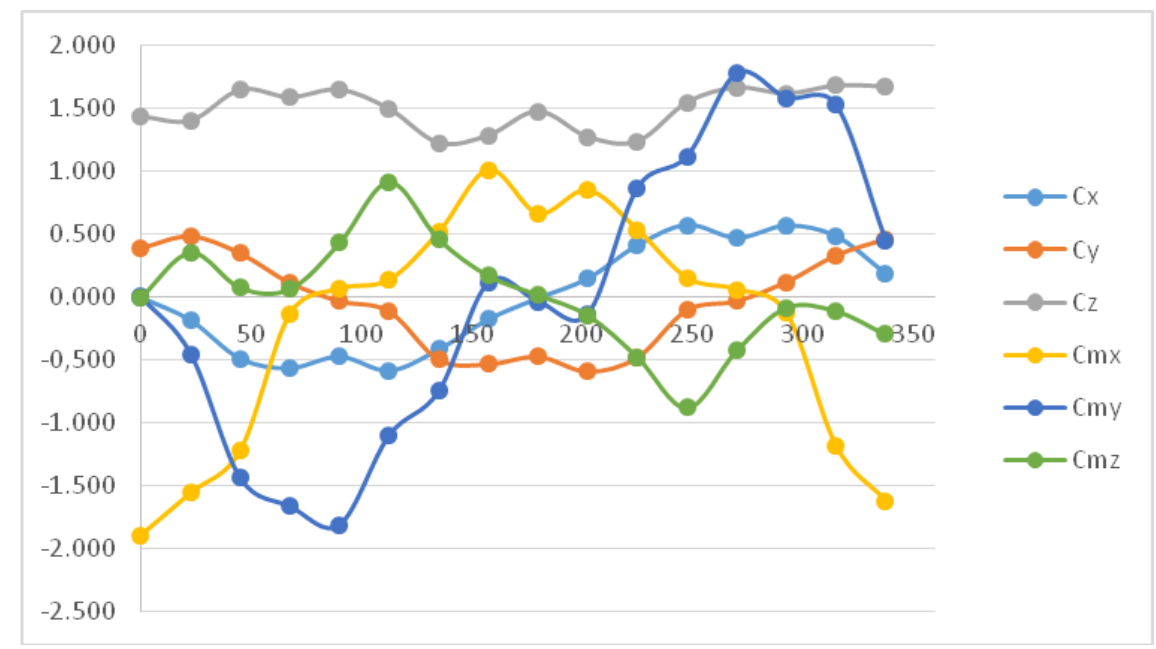

Fig. 4. The schedule of aerodynamic coefficients dependence $\mathrm{Cx}, \mathrm{Cy}, \mathrm{Cz}, \mathrm{Cmx}, \mathrm{Cmy}, \mathrm{Cmz}$ at change of attack angle from $0^{\circ}$ to $360^{\circ}$ (Perm).

For the airport of Rostov-on-Don max load occur at angles blowing $0^{\circ}, 30^{\circ}$ and $210^{\circ}$ $(\mathrm{Cx}=0.968, \mathrm{Cx}=0.726$ and $\mathrm{Cx}=-0.569$, respectively $)$ and at angles of airflow in $45^{\circ}$ and $240^{\circ}(\mathrm{Cy}=1.535$ and $\mathrm{Cy}=-1.04$ respectively).

For airport of Perm maximum loads occur when blowing corners $90^{\circ}$, and $270^{\circ}(\mathrm{Cx}=-$ 1.089 and $\mathrm{Cx}=1.781$, respectively).

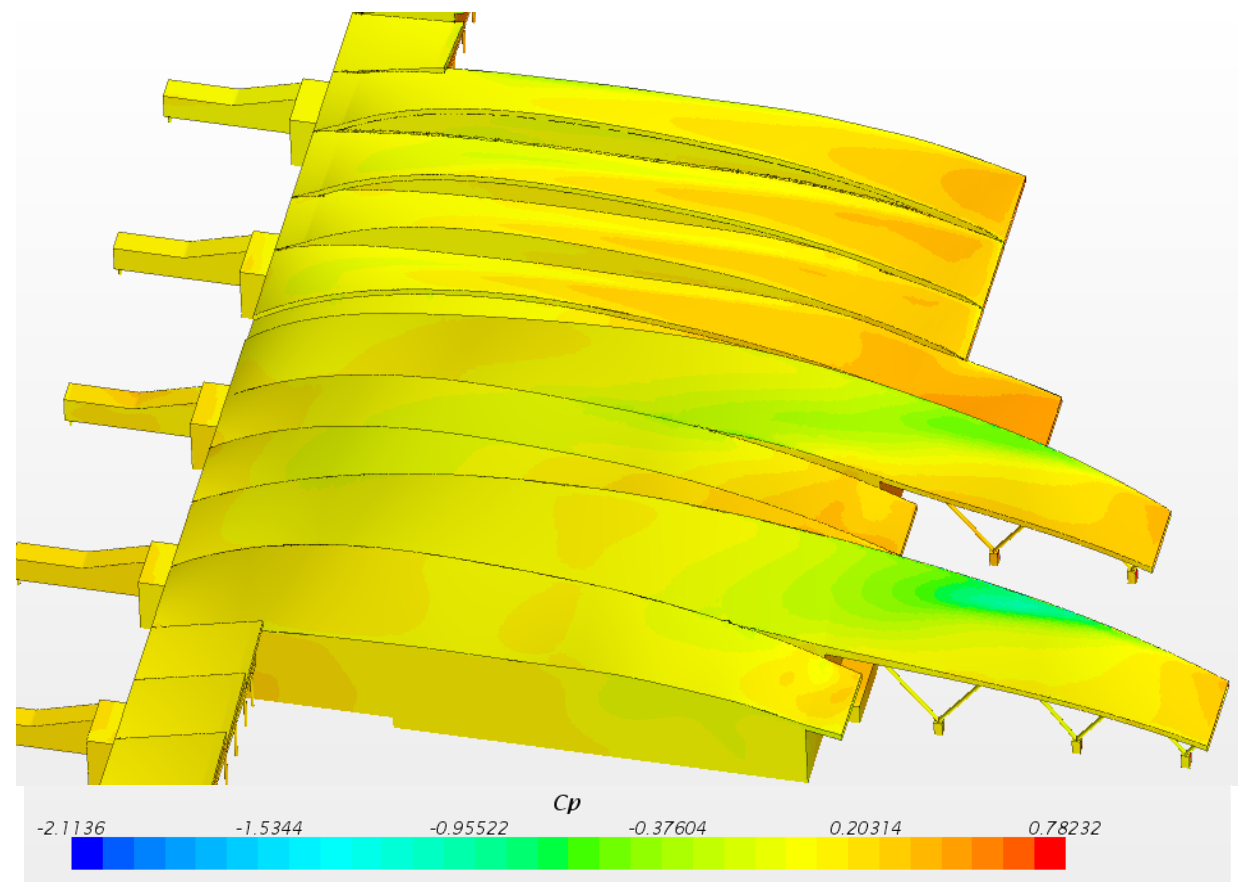

Fig. 5. Distribution of aerodynamic coefficient of pressure values on the surface (Rostov-on-Don). 


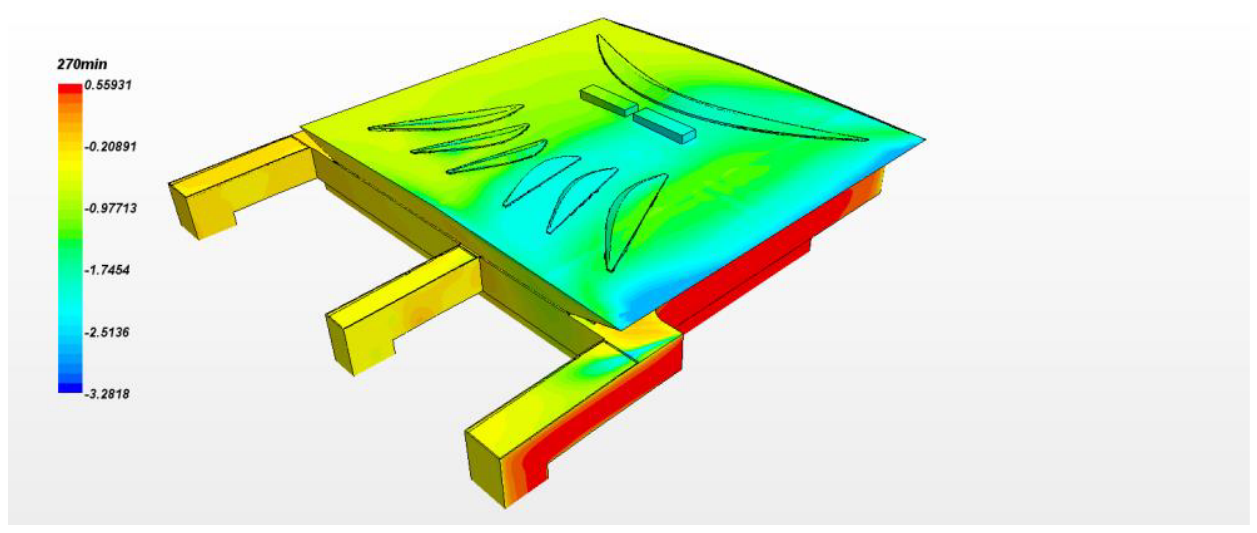

Fig. 6. Distribution of aerodynamic coefficient of pressure values on the surface (Perm).

Bioclimatic comfort space near the airport is connected not only with the speed of the wind, but also with deposition of snow and necessary maintenance works on clearing of snow and ice. Wind effects and snow are subjected to the passengers during the boarding and disembarking from the domestic airport transportation, as well as airport staff, who spends a long time in the open space. In this connection, obtained by experiment results help to identify problem areas on bioclimatic discomfort and avoid their placement embarkation and disembarkation of passengers in domestic vehicles airport, as well as to optimize the allocation of posts and technological platforms on which it is supposed finding of the airport staff.

Criterion of wind speeds comfort for the evaluation human presence close to the airport was used for the winter, and is in the range from calm to $3 \mathrm{~m} / \mathrm{s}$. For evaluation the short stay on street (10 minutes) in relative discomfort it was assumed the value of wind speed is $7 \mathrm{~m} / \mathrm{s}$, based on the recommendations given P.P. Kovalenko and L.N. Orlova in the chart the effects of wind and temperature in the environment [10].

It should also be noted, that the most vulnerable structures of the building in this case are telescopic gangways for boarding and roofs, or rather the airports terminals coating systems. The telescopic ladder is the mobile part of the building for the passage from the aircraft in the airport building, without an intermediate exit to the street. His device is a telescopically moved apart corridor consisting of several modules, which can also be moved relative to the aircraft: horizontally on the ground using a wheel and suspended vertically with electro- or hydro-lifts as well as the position of the entrance doors at the different types of aircraft different. During using the parking lot with a telescopic ladder first aircraft usually rides to park yourself under own engines. After stopping the aircraft, operator telescopic ladder set it to the front door of the aircraft. Thereafter, telescopic gangway must keep track of the aircraft fuselage vertical displacement (due to its loading and unloading) himself and move vertically to the extent necessary, thereby maintaining its position relative to the door. In connection with this, used structure should have flexible metallic insert parts of variable geometry, which is very sensitive to the wind and snow loads. In winter the telescopic ladder can freeze and damage the aircraft, if dock space was not properly examined to the possibility of the formation of ice due to melting of accumulated snow.

The question of specification and snow cleaning optimization of airport roof is also in many respects interconnected with the data obtained during experiment study. Due to the winter temperature drops at the airport roofs and canopies a frost is likely will be formed. Along with snow, hanging from the roof and icicles edges, it can damage the roof and gutter system. It is not only the risk of damage to the airfield equipment, but also a real 
threat to the health and lives of people passing by. To reduce risks and protect the surrounding area, the results of the experiment must be considered in the development of regulation works on the snow and ice roof clean, including the cleaning of the pitched roof areas of snow on the width of $1.5 \mathrm{~m}$. Such work of the roof cleaning is recommended to avoid the risk of falling snow masses from the roof and it is used under extreme weather conditions. Cleaning roofs from snow and ice belongs to the category of particularly dangerous works carried out at height, require compliance with safety rules and taking into account the weather conditions. At differences of external air temperatures with transition on positive on metal cattle sites of roofs (except for a roofing covering) the roofing covering, trenches and covers trays established on water reception funnels have to be completely cleared. This is necessary to avoid the formation of ice dams.

It is recommended to clean the roof of the airport in Perm in extreme weather conditions, partly for supporting the work of drainage funnels and testing the thickness of the snow cover at the light and aeration lanterns. The airport building in Rostov-on-Don has largely pitched roof, which requires complete removal of snow around the edges in case of extreme weather conditions due to the danger of icing. In both buildings, telescopic ladders receive considerable wind load without serious snow deposits. Thus, the obtained results allow us to estimate not only the necessary requirements for snow removal of the roof and the load on the roof structure, but also to predict the snow load on the cover and flexible insert of telescopic ladders.

This work was financially supported by the Ministry of Education and Science of the Russian Federation within the framework of the state order to MGSU №2014/107 project "Fundamental studies of wind effects (including extreme) to the unique building and bridge structures".

\section{References}

1. SP 20.13330.2011, The updated edition of SNiP 2.01.07-85 * "Loads and effects. (2011)

2. American Society of Civil Engineers. Minimum design loads for buildings and other structures. ANSI/ASCE (1998)

3. MDS 20-1.2006. Temporary regulations for loads and impacts of destination, acting on a multifunctional high-rise buildings and complexes in Moscow (2006)

4. E. Simiu, R. Skanlan, The impact of wind on buildings and structures (1984)

5. V.G. Gagarin, S.V. Guvernyuk, A.S. Kubenin, A.A. Sinyavin, Bulletin of the Department of Civil Engineering of the Russian Academy of Architecture and Building Sciences 18, 151 (2014)

6. O.I. Poddaeva, G.V. Orekhov, I.V. Dunichkin, O.A. Kochanov, Proc. Integration, Partnership and Innovation in Construction Science and Education Scientific publication, 133-138 (2012)

7. O. Flamand, Czasopismo Techniczne 12, 51-61 (2015)

8. A. Zasso, D. Rocchi, P. Schito, EACWE 5 (2009)

9. P.S. Churin, J.S. Buslaeva, International Journal of Applied Engineering Research 10, №20, 40841-40843 (2015)

10. P.P. Kovalenko, L.N. Orlova, Urban climatology, 142 (1993) 